\title{
Learning Links: A study of narrative learning through games with The Legend of Zelda: Windwaker
}

\author{
Suzanne de Castell \\ University of Ontario Institute of Technology \\ decaste@mail.com \\ Emily Flynn-Jones \\ York University \\ finalfinalgirl@gmail.com
}

\author{
Jennifer Jenson \\ York University \\ jjenson@edu.yorku.ca \\ Kelly Bergstrom \\ York University \\ kellyberstrom@gmail.com
}

\begin{abstract}
This paper details the iterative design and preliminary findings of a school-based study of whether, what and how students can learn about narrative---a foundational learning goal in elementary language arts - by playing a narratively structured commercial game. Working with a grade 6 teacher, we ran 3 lunchtime programs that involved playing The Legend of Zelda: Windwaker, under three different conditions, from a minimally-interventionist "just play" approach, to an explicitly instructionist "knowledge delivery" one. Only in the third (explicit instruction) phase of the project were we able to generate evidence of significant "learning through play". We conclude by considering impediments, both practical and theoretical, that stand in the way of bridging the persistent gap between "claims" and "evidence" in digital game-based learning research.
\end{abstract}

\section{Introduction}

Understanding narrative, including both theoretical understandings of what a 'story' is, its cultural functions and technical structures, and narrative competence in interpreting and composing in storied forms, is a foundational learning goal in the elementary language arts curriculum. This paper describes our efforts to devise a research design for studying how playing digital games might help support the goal of building narrative competence, (as broadly defined above) and documents the range of impediments, obstacles, and challenging questions that impede games research in school settings.

Two major assumptions undergird many schoolbased studies of games and learning: first, that games are more attractive than traditional teaching materials to $21^{\text {st }}$ century learners $[8,9,23]$; second, that games are able to inspire self-directed learning that supports educational goals $[9,24,25]$. Authors making one or both of these assumptions usually draw upon Gee [12, 13], whose work has been highly influential to educational games researchers, but has been criticized for lacking empirical data to support its claims [17]. But what kinds of empirical data are we talking about here, and how might we go about securing it?

The relative ease with which objective and welldefined learning goals can be measured contributes, very understandably, to a bias in games and learning research towards studying the development of factual, scientific, and arithmetic forms of knowledge. An illustrative recent study that analyzed the OECD's (Organization for Economic Cooperation and Development's) 2012 Program for International Student Assessment data from over 12,000 Australian school students found that students who played online games regularly (almost daily) scored 15 points above average in maths and reading tests and 17 points above average in science. (Students' engagement with social media, by contrast, resulted in $4 \%$ lower average scores.) Researcher Alberto Posso, explained in an interview about the study: "When you play online games you're solving puzzles to move to the next level and that involves using some of the general knowledge and skills in maths, reading and science." Such correlation-based research cannot, of course, prove that the critical variable is videogame play, nor do we yet enjoy a wealth of conclusive research on what and how digital gameplay might contribute to education, even to the most straight-forward factual of learning goals. But game-based learning research that aspires to educational value and significance has to be broader and deeper, and specifically, it has to include thus far relatively neglected questions about how gameplay might possibly advance cultural, humanistic and social learning, and it has to do so in contexts far less well controlled than those in which learning is assessed through objective standardized testing of factual knowledge.

With that purpose in mind, we are engaged in a multi-year study addressing educationally important, but far less well-defined, learning goals of the broader and deeper kind: narrative understanding, musicality, spatial cognition, and leadership development, 
situating these studies within the 'everyday' classroom and afterschool activities of 'everyday' public schools. We seek to generate evidence of a kind educators will see as both salient and persuasive [26], either by replicating what appear to be the best examples research into each of these learning objectives or, where strong examples cannot be identified, designing a study capable of generating such evidence. The work reported here was a very preliminary pilot study, a kind of design-based research [3] about research, intended to just 'look and see' what and how we might learn about what and how students can learn from playing a narratively framed commercial game. We wanted to design a school-based study capable of yielding persuasive, if not conclusive, evidence of whether narrative competence might be advanced through digital gameplay, and we needed to figure out what kinds of evidence to look for, and how to look for it. How could we show that - and identify the circumstances under which - gameplay might support that set of learning goals central to the elementary language arts curriculum that involve narrative understanding?

Two distinct questions are at stake here: The first is a 'genre and learning' question about learning through narrative: What and how do players learn from games that are narratively structured? The second asks about how gameplay might support learning about narrative, as a specific learning outcome. We were interested in both questions. Could digital games serve the way novels traditionally have done, to support the development of children's narrative understanding? With respect to learning through narrative, our working assumption was that a narratively structured game would likely offer most opportunities for players to learn about narrative, although we appreciate that learning through narrative by no means necessarily promotes learning about narrative, the latter being, as it were, at different, (meta-cognitive) 'level'.

\section{Related Literature}

To date, research on whether and how games can support narrative understanding is relatively sparse, and we have found no studies that yet provide strong evidence of advancing this specific goal. That said, Sasha Barab and colleagues have written about the widespread design and use of Quest Atlantis (QA) by educators and over 25,000 students in the U.S, arguing that $Q A$ provides an "immersive narrative" [5] that helps produce successful learning outcomes in the areas of science and social science [4]. Dickey's work $[10,11]$ looks at the impact of narrative design on player choices and learning in a designed game space. Like Barab and colleagues, she reports on a game she and her team have designed, Murder on Grim Isle (MOGI). Studying 20 players of MOGI, she found that players used their prior knowledge of conventional narrative structures rather than the designed narrative of MOGI to make sense of what was happening in the game [11]. Others [2] built and studied a game to teach a medieval history of Amsterdam, and found that students ignored the background story to the game, to focused instead almost entirely on the tasks that they needed to complete the game. Finally, and reaching more broadly, a recent review by Novak [18] examined 'storyline-enhanced learning'. She found only 11 empirical studies that examined the impact of storybased interventions on students. She found generally a tension between using commercial off the shelf games (COTs) as we do here, and the labour intensive process of designing and developing story-line driven interactions. She concludes by pointing out that: "Stripping down a storyline design element from storyline-enhanced learning environments produced either non-significant or better learning in most of the studies" and found no particularly strong benefits to narratively driven games [18]. There are of course more and less effective and engaging narratives, and possible learning benefits of narratively structured texts (including here both traditional and digital texts, of which games are but one example) could be missed for that reason.

\section{Context and purposes}

We had an opportunity to run a lunchtime program at a large, low-mid SES, suburban elementary school in Ontario, Canada. The participants (21 girls and 13 boys) were all sixth grade students (ages 10 and 11). The Ontario Language curriculum for this grade has a focus on story structure, composition, contextual analysis and critical comprehension, as well as the development of media literacy -the ability to critically decode non traditional (e.g. visual or auditory vs. language and print-based texts) [19]. In this school, the principal and teaching staff expressed a keen interest in using digital technologies to enrich and support student success, and they were open to looking at the possible educational contributions of playing videogames. We wanted to find out whether and how playing digital games in a school setting might contribute to students' development in, specifically, story structure, narrative composition, contextual analysis, critical comprehension and decoding of non-traditional forms of text. Beyond these targeted learning outcomes, we wanted, also, to see if we could identify other kinds of learning outside of and different from these very much school-driven learning goals.

\subsection{Participant selection and recruitment}

The partner teacher suggested that a full lunch period once a week for a minimum of 8 weeks would result in the highest possible attendance for participants. There 
was to be a 3-week winter break, and we fully expected (and experienced) intermittent absenteeism and tardiness, as students were encouraged to volunteer for various fundraising activities including selling milk and snacks in the hallway before the first half of the school-wide lunch period, or acting as a hallway and/or playground monitor. So we set out a 12-week program, in the hopes that might give all of our participants enough time to deeply engage with the game. Even with all our efforts to plan around planned and unplanned interruptions, there were always students who would arrive late and/or have to leave early to attend to their other school-related commitments.

Because of the constraints on students' availability, we were assisted in participant recruitment by the partner teacher, who was more familiar with the schedules of the grade six students than any member of the research team, as she was best able to select participants depending on their schedules and levels of interest. Offering three consecutive sessions meant everyone had a chance to participate no matter what their different schedules.

The 'permeability' of lunchtime scheduling, as well as the fact that we were using students' free time, meant student participation in the project was voluntary in the strongest sense of being 'freely chosen'. For that reason, we stated out with a series of maximally unrestricted game play sessions where students would be invited to play a popular "commercial off-the-shelf" game, with the only demands on students being the completion of a questionnaire before and at the end of their 8-week gameplay sessions. We recruited new participants in mixed sex groups in groups 1 ( 6 girls/ 6 boys) and 2 (6 girls/7 boys), and, for reasons we'll explain in time, recruited a $3^{\text {rd }}$ all-girls group of both new and returning participants ( 9 new and 9 returning). The small number of participants meant our work would be qualitative: looking at students' oral, written, interactive and playbased performances principally for suggestions and ideas and examples.

\subsection{Software \& hardware: A Cautionary Tale about selection}

The game we selected for this project was The Legend of Zelda, a much loved franchise. With many characteristics of the roleplaying genre, Zelda features an emphasis on character and narrative development. The first game was released in 1986 and the series has enjoyed a large player base over the years, and has been critically lauded in the popular press, celebrated for its rich mythology, narrative and world building, and its engaging gameplay [1, 16,22]. Zelda games are generally rated "E" (suitable for "everyone") by the Entertainment Software Rating Board (ESRB), a classification that makes the game an acceptable vehicle for use with elementary school-aged students.

The Zelda series follows the adventures of a young male protagonist, Link, and the series' extended narrative backdrop made Zelda games appear a good medium for supporting a study of narrative learning in and through digital games. The specific game selected for this study was The Legend of Zelda: The Windwaker which featured the same narrative conventions as mythic narrative: the rise of an evil, some disturbance of the status quo in the fictional world, such as the kidnapping of a princess or loved one, which serves as a call to action for the hero. We presumed that playing through a narratively structured game would support both students' learning, and would enable us, as researchers, to identify ways---and specific criteria-- to gauge what participants might be learning through free and 'untramelled' play, about story conventions and components.

To minimize a possible confound of some participants having already played the game, we chose an installment in the series that had been out only a few weeks at the time of the study: a re-mastered version of a game originally released in 2002, before the majority of participants were born.

The start date of the study coincided, also, with the release of Nintendo's latest gaming system, the Wii U. The Wii U was a departure from the motion controller used by the Wii, and instead of the intuitive mimetic control system involving a motion-based controller mapping player movement to the game diegesis, and a nunchuck device, the Wii $U$ is controlled by a game pad that features an embedded touch screen. By selecting both novel gaming equipment and a game that was new to all participants we minimized the advantages seasoned game players might have.

\section{Phase One: Free Play}

This project's first group was one that supported free play and minimal instruction. In this phase we observed, documented and interpreted game-based learning interactions from the simplest possible starting point: the presumption that if good games support learning, we need to find out much more about what players are learning, and how that happens.

Our questions as we embarked on this lunchtime game club project were: What, if anything, do players new to Zelda learn about the game and/or its welllauded narrative, just by playing it over successive sessions? What, if anything, do they learn about narrative more generally that might support curricular objectives for developing students' narrative understanding?

On the project's opening day, participants were introduced to the study, invited to fill out a pre- 
questionnaire about prior gaming experience and any familiarity with the Legend of Zelda games, and asked if they could name characters from the game by recognizing them visually in a picture. Next, participants were introduced to the Wii U technology and made Mii characters. Sessions two through eleven were play sessions with the game. Participants were teamed up in same-sex pairs, as previous research has indicated that grouping enabled girls especially to take equal charge of the technology (Reference removed for peer review).

From session two onwards, participants would come to the library at the start of the lunch period and would be free to begin playing as soon as they had eaten. At the beginning of each session students were reminded of the project's research goals, including that we were interested in finding out what story they were experiencing through play, what the main elements of that story were (characters, plot) and we asked them to pay particular attention to the game's story. Researchers set a timer to remind the pairs to switch half way through the session so that both students would have an equal chance to play.

Inevitably, some participants were not getting as far in the game as others, so in session eleven, the penultimate session, walkthroughs (a text-based game guide) were provided to help stragglers catch up. The walkthrough was available on a PC across the room from the play stations where the students were situated. This turned out to be an ill-advised decision for two reasons: the supervising teacher had called the resource a 'cheat', which stigmatized use of the walkthrough; and the distance to the resource - a very public "walk of shame" - was too great. So students continued to ask each other for help or remained at bottleneck points for the remainder of play.

Session twelve, our final meeting with the Phase One participants, broke from the pattern of the previous sessions. Researchers provided a pizza lunch, and brought a selection of other (non-Zelda franchise) games to play. Students were asked to complete a postquestionnaire that included repeating the character identification sheet from session one. Exit interviews were conducted, in which participants were asked a series of questions about what they had learned about the story of the game.

At the conclusion of Phase 1, no one had completed the game, understandably enough, since it normally takes 20-25 hours to 'beat'. Also understandably, both of the two player-teams that progressed the farthest were composed of male students. We were less interested in game acumen, though, than in trying to discern any learning outcomes that might be salient to students' developing narrative understanding through gameplay-though it would certainly be interesting to see if these proved to be related. Students' responses to post-play questions about narrative were informative, and sobering: most could not correctly respond to basic questions such as: "What is the story told at the cut scene at the beginning of the game?" "What is the title of the game you played?" "Who is the main character of the game?" These responses were consistent with researchers' observations throughout the project that participants consistently described their play in terms of mechanics and the actions they had taken (jumped, fought, etc.) and problems they had encountered with the game, rather than in terms of its story.

4.2 (....and Lessons Learned) Phase One had extended over twelve weeks with a three-week break during the winter holiday. The break very evidently interrupted progress, and it was obvious that participants who had been away from the game for three weeks needed to get reacquainted with it. In light of this, subsequent phases of the project were reduced to eight weeks, and more purposefully scheduled to avoid similarly extended school breaks.

It became clear from the first look at Phase One's data that it was not sufficient to simply remind students to "focus on the game's story". We soon discovered the ludic elements of Windwaker greatly overshadowed the ways in which participants might experience the narrative of the game or the logic of its story. Moreover, we saw that those participants who frequently skipped through dialogue in order to "get back to the game" faced real problems in making progress, as much of the in-game instruction and/or hints are buried in the dialogue and text, so these students frequently became stuck.

For the next iteration, we modified the research protocol to add structure to each play session and to scaffold students with daily objectives intended to encourage them to engage explicitly with the narrative of Windwaker rather than remain, as they appeared to be, overwhelmingly focused on gameplay and mechanics, failing to experience the game as story, even as we kept reminding them to look for the basic elements of character, setting, problem, crisis, and resolution.

5. Phase Two: Structure \& Play Phase Two was similar to Phase One insofar as students played the same game, play sessions happened over lunch hour, and students brought lunches to the library and began playing once their meals were finished. We also used the same pre-post questionnaire. For reasons indicated above, the project's second phase was modified in two ways. First, to help participants who intentionally or inadvertently skipped over important information in the game to make better 
progress, we introduced walkthroughs, but this time 'legitimately', providing each group with an iPad connected to WiFi from a portable router and internet hotspot. Pre-vetted walkthrough documents were loaded on the iPads for students to use and we recommended that while one partner in each pair was playing, the other could use the walkthrough and act as a 'navigator' so that both students had an assigned role at all times, one mobilizing traditional literacies, the other, digital literacies.

The second change to the research protocol was the addition of daily activities intended to keep students focused on the narrative unfolding in the game. After observing gameplay in Phase One and now knowing roughly the speed at which participants would progress, the research team created a list of a list of "daily questions" for students to answer at the end of each play session. Each question aligned with items in the sixth-grade language arts curriculum and focused around a particular narrative milestone of gameplay: we asked participants to describe characters they met, for instance, to create a backstory for a minor character, or to discuss the change in setting between levels. These questions were printed (one question per sheet) and given to each pair at the start of the play session. Keeping the questions near their play areas, we thought, could serve as a visual reminder to pay attention to the story of the game, in order to answer the day's question. In the last five minutes of the lunchtime sessions, all participants were instructed to save their games and to use iPads to record their answers to the day's questions in the form of a 'video diary'. While these daily questions did seem to help participants focus on particular aspects of the game story each session, however, this did not translate into any significant difference in answering the questions on the final session over those of phase one participants.

6. Third Time Lucky? New Questions, and a Gender-focused Re-design

In our team's previous studies of games and learning, gender differences in access and expertise had formed a focus of study (reference removed for peer review), so inevitably that issue resurfaced in this study as well. Pre-program questionnaires demonstrated that while girls generally said they played games, they reported playing less often and were significantly less likely to be familiar with the Zelda franchise than boys. We had seen that the girl groups progressed through the game more slowly than boy groups, and despite our attempts to organize same-sex play groups, male peers would go to girls' play stations, take the controls away and play for them through more difficult sections of the game. So although we could with confidence presume we were seeing how the male students made progress and developed mastery, this practice, observed throughout the project's first two phases, made it impossible to accurately track how their female counterparts were progressing. Seeing that we had, at best only half the story, we decided to form a girls-only group for the third phase. Had this been a formal study, such a modification would have invalidated our results: whereas before we'd been playing with apples and oranges, now we were playing with oranges as the only fruit, making any data aggregations or comparisons impossible. However our objective in this project was to figure out how we could design a study of gamebased learning capable of demonstrating how specific subject-matter within the formal school curriculum could be learned and/or enriched; our primary interest was in identifying unexpected challenges and obstacles, and trying to look at learning in new ways so that what players were learning could be discerned even though it might not assume familiar forms. Being unwilling to conclude the project without confidence that our study design could actually allow us to understand what and how the girls in the group might be learning, we decided that in a project to inform the design of a formal study, we could make that major, and otherwise self-undermining, modification.

\section{Phase Three: Gendered Play}

Of the Phase Three (all-girl) participants, half (9) were returning students who had taken part in either Phase One or Phase Two, and half of the group were newcomers (9), a condition intended to resemble typical conditions of boys' play in which we can normally expect a fair number of experienced players in any all-boys group. The pre-questionnaire was administered, however, only to those who had not yet played the game, as we already had baseline data on their gameplay habits and experience, but all parties filled out the character identification sheet in session one, so we had a sense of where their prior experience with the game positioned them, relative to first-time participants. With a larger number of participants (18) in this all-girl phase of the study, the player groups were larger. New participants were grouped with past participants who were the 'experts' and who were instructed to help newcomers.

Since the daily questions had been successful in keeping Phase Two participants on task, although not to any great effect in terms of learning outcomes, we continued with daily questions for Phase Three. Returning participants from Phase Two answered the same questions as before, and we added "what is your favorite game character and why?" as well as questions about whether or not they improved playing and what they thought about the game in general. We also continued the use of walkthroughs in player groups. Returning participants were asked if they thought 
they'd learned more about the Windwaker narrative in their second play-through, and if so, what they learned, and how they felt about their competence and overall skill in playing the game. The 'experts' demonstrated - and expressed - significant development in both their understanding of the game's narrative and in their confidence playing the game. It was only in this third phase that we found a way to both adequately engage students in intensive and focused gameplay (as opposed to making selfies, surfing the internet, surrogate playing of the 'hard parts', or Facebooking), and two elements made this possible: a structured didactic activity explicitly focused on student learning of elements of narrative, and, very significantly, participant 'compliance'. There was willingness among these young female students to assume the role of the 'ideal player', and to play through the game as it was designed to be played, leaving distracting anomalies and inventions such as "pig-tossing" aside. This level and kind of compliance, we know from our previous school-based fieldwork, is far more typical of girlsonly than of mixed sex groups.

\section{Data Collection}

Throughout all three phases of the project, despite iteratively modified approaches, data collection procedures remained consistent. In each session 2-3 researchers were present primarily in an observational role, and could offer assistance with gameplay, but only as a 'last resort'. When asked for game-related help, researchers were instructed to first offer prompts or clues (including suggestions to consult the walkthroughs in phases 2 and 3) rather than to provide direct explanations. If that assistance failed and more detailed instructions were required, researchers were not to take the controls away from the participant, but to verbally explain and gesturally indicate how students could overcome their obstacles. Ideally, this 'hands-off' support ought to have encouraged participants to troubleshoot together, but in fact it resulted in novice players handing over the controller to more experience participants to quickly move past challenging puzzles.

Researchers took detailed field notes throughout the project, commenting specifically on the following: productive or combative group interactions, genderbased performance, interesting or aberrant types of gameplay, and game-focused discussions about narrative and/or about puzzle solving. Session notes also included reflections on how researcher presence or actions might have impacted proceedings and what possible kinds of research impacts to look out for. In terms of technology-supported observation, at each lunchtime session one group would be videotaped at play, allowing for the capturing of complex interactions that might be missed in live observation, and iPad recordings of each session's assignments allowed us to see how groups worked together to answer narrative-based questions, or to avoid answering them. At the end of the project, all video data (from the video recorder and iPads) were transcribed and field notes compiled for review, summary and analysis. In what follows, we share some of the findings we think may be most significant for other researchers considering embarking on studies of this kind and, more specifically, game-based learning research in school-based settings.

\section{Analysis: Skippable Story}

It was only by watching our participants encounter the Zelda franchise for the very first time that we were able to see, notwithstanding its reviews to the contrary, just how little 'story' exists within the Windwaker gameworld, particularly in its earlier portion. ${ }^{1}$ This is a game that has received high praise from reviewers and popular acclaim from fans for its narrative (see also, however [26]). Windwaker's opening cut scene is a non-interactive video collage of text and still images of ancient scrolls. This is a significant point of narrative delivery [10], which provides players with the elaborate backstory of a forgotten hero prophesied to return, and a fallen evil threatening to rise again. It is, however, possible to skip this sequence by pressing a button on the control pad, and some participants were seen to do this despite being instructed to pay attention to the game's story. Skipping the cut scene means skipping the orientation to the game and its narrative introduction, as well as the backdrop for the story's primary tension, and its foreshadowing.

\subsection{Mechanics and Verbs}

At each play session, researchers would circulate throughout the library play space to observe participants' progression through Windwaker. A member of the research team would do a verbal checkin with each pair of students. When we asked players to describe what was happening in the story, we began to observe an interesting pattern: participants most frequently responded by describing their immediate context. They are in a town, they are talking to a man, looking for someone, swimming in the sea, throwing objects, collecting items, sword fighting, jumping to different locations. There were, in short, a lot of verbs

\footnotetext{
${ }^{1}$ A very helpful reviewer of this proposal has astutely noted that it might be largely the terms of traditional (linguistically conveyed) narrative that the Zelda stories can appear to be 'stories' at all, and that using for instance, a proceduralist analysis better-suited to the medium might reveal that narrative is not the core of the Zelda games at all. This observation is rather similar to the general point we seek to make about our persistent failure to detect, in valid and reliable ways, educationally significant 'learning outcomes', which is that if we only employ traditional terms and concepts as our criteria, we might not see much of the learning that is actually being accomplished through digital gameplay.
} 
involved in response to requests to describe what was going on in the game. Games are, of course, composed of mechanics, the things a player can do by entering commands into the computer. As types of actions, game mechanics are most readily expressed as verbs. With a focus on the immediate situation, participants were often unable to make connections between mechanics and plot, including, for instance, why they were doing the things they were doing in the game and how their actions were part of an evolving story. Adding question prompts helped re-focus students on the story of the game and how their actions in the game might fit into a larger story arc, but our preliminary analysis indicated that it takes some heavy scaffolding to move student-players from understanding their play as mechanics, to understanding the story of the game, or understanding the game as a story at all, let alone any more sophisticated grasp of the game as an "interactive narrative" [20].

\subsection{The Ambiguous Zelda}

One significant indicator of failure to apprehend the game's story was the good deal of confusion about who 'Zelda' actually is. Even after playing for eight weeks, the majority of participants mis-labeled the protagonist as 'Zelda' on their character identification sheets. For those unfamiliar with this game series, the main character of Windwaker--and all other games in the series--is Link. Zelda is a princess that Link often has to rescue. However, this is never made explicit in the Windwaker game.

Reflecting further on this repeated occurrence, we realised that Link is not directly referenced in many Legend of Zelda games - not just Windwaker, meaning that identifying Link involves drawing on historical and intertextual knowledge of the game series. The appreciation of the 'story' of the Legend of Zelda expressed by fans and the game's press, then, involves reading not intensively but extensively across texts over time, and we did not properly anticipate the importance of paratexual knowledge for accessing the narrative embedded in the game we selected.

\subsection{Participant Play Practices}

Observing our participants at play through three phases of this project, it became evident that the structure of The Legend of Zelda: The Windwaker, like other such games, affords a variety of play approaches and interactions not necessarily part of the intended progression. While there is a set story and an intended path for the player to follow, Windwaker has, as well, some elements of a sandbox-style gameworld where side missions or mini-games can be uncovered that bear little, if at all, on the overall plot, and other, unruly, varieties of play can be concocted. Our participants engaged in a number of play practices unexpected and not always productive in terms of advancing their engagement with the narrative which was both the explicit activity objective, and the scripted goal of the game.

In addition to seeing players mistake side events for main elements of game progression, we observed that participants would sometimes attempt to use elements of the open world to create new activities that were (to them) more interesting than progressing through the main story arc. A number of such play practices were observed over the course of the project, and one that engaged most of the participants in its first ("freeplay") phase was a practice the researchers dubbed "pig tossing". One of the NPCs early on in the game is a pig-keeper, whose pigs have escaped. When spoken to, the NPC asks the player help to catch and return his drove to their pen. To do this, the player must master a complex button sequence that lets them sneak up on the pigs, grab them, hold them aloft the protagonist's head and finally release them with a strong throw. Instead of following the objective set by the NPC to return the pigs to his keeping, participants initiated a meta-game that involved throwing pigs in unusual ways - off a cliff and into the ocean, for example. This distraction lasted across multiple play sessions and kept players from making progress in the game or delving deeper into its narrative.

What participants were engaging in when "pig tossing" was discovering the affordances of the game system. "Windwaker" offered the player a number of possible diversions from its central story and objectives. In building this study, we had fallen into the trap of imagining the 'ideal player': one who would find the most obvious and efficient path through the game, who was already familiar with the major story arcs of the series. Even participants who followed the walkthroughs did not conform to these expectations of play. Problematic assumptions of this kind surely undergird some of the major claims about the educational value of games: claims that pertain to specific highly regulated and pedagogically mediated contexts of play largely undisturbed by outside influences and attractions - and that anticipate particular game-compliant behaviours. Educators considering using commercial games for education need to know, though, how school-based gameplay of this kind actually happens "in the wild", because that, and not the 'goodness' of a game, just might be what principally shapes and constrains what is educationally possible through its means.

\section{Discussion and Lessons Learned}

This paper has detailed an exploratory, multi-phase project whose specific objective was to arrive at a 
study design that can provide persuasive evidence of the potential for games to support the development of narrative understanding. Through an iterative research design process, we identified a range of impediments to realizing that goal, some of which derived, ironically enough, from our own expertise with games, and from fundamental assumptions that undergird contemporary discourse on games and learning: a contradiction between the way we speak and think of a game as a 'set text', and players' lived experiences of playing it, and playing with it.

\subsection{Games from above and below}

In terms of this project, the game selected appeared to instantiate the properties needed to support key curricular aims of the sixth grade language arts curriculum concerned with understanding the logic of stories and developing competence in recognizing, interpreting and constructing narrative accounts. But the "player reality" for our young participants encountering the game for the first time, with at best half the playing time needed to complete the game, and in isolation from the larger Zelda storyline, was markedly different. Dan Golding [14] offers a useful discussion illuminating divergent perspectives on the 'same game' that may be helpful for, among others, educators considering attempting educational uses of digital games. He suggests that discourse on games takes a 'from above' position; playing a game happens, as it were, 'from below'. Like de Certeau's description of the advantageous perspective of New York City offered from the 110th floor of the World Trade Center, games are discussed and conceptualized from a good distance. Golding explains: "From this perspective, the theorist can totalize videogame space just like the tourist can totalize the city of New York; we can see the ebbs and flows of spatial design, perhaps drawing conclusions from apparent authorial intent or configurative skill. From this perspective, the videogame theorist reads space as if it is a whole and total text" (p. 118).

Thinking of games 'from above' we can see "things as they connect and work together" [14]. From this distance, a game starts to look more like a map or a walkthrough. In this understanding, the 'from above' position is that of the 'strategist', whose advantageous view allows a plotting of territory and a discernment of the most effective ways through it that is, however, a position quite at odds with the played experience of games. The active player views the game 'from below'. In this position the player is negotiating with their immediate surroundings, doing the best they can to improvise tactically in a space of which they have both limited knowledge and partial view. This disjunction between the researcher's from above perspective and the from below perspective of our classroom-based player-participants resulted, we now see, in our often working at cross-purposes from them - we were, in effect, not working with the 'same game'. This realization calls seriously into question whether indeed the playing of a narratively driven game can, in the playing of it, cultivate narrative understanding - it may be that this can be accomplished

\subsection{How research ecology matters}

Field research is always subject to climatic conditions within which it is conducted, and this study was no exception. Its multiple barriers and impediments included teacher effects in the form of actions that undermined the seriousness of the study, the framing of study participation as a reward for good behaviour and the dubbing of the supporting walkthrough documents as 'cheats'; distractions and disruptions born of the shared social space in which the study was conducted; and the limitations of resources and available space and time as well as the evident advantages of prior knowledge and experience of games for competently playing, progressing and learning from games.

One of the more significant findings supports the by now oft-rehearsed criticism that we cannot presume enhanced or inherent digital literacy among $21^{\text {st }}$ century learners who have grown up with new technology, and "have spent their entire lives surrounded by and using computers, videogames, digital music players, video cams, cell phones, and all the other toys and tools of the digital age" [20]. This underlying presumption that students of the digital era are 'tech-savvy" and that these 'digital natives' learn 'differently' has excited much enthusiasm about the ways technology should be incorporated into " $21^{\text {st }}$ Century" pedagogies. When we offered our young participants hands-on experience with a novel gaming technology, however, most young so-called 'natives' exhibited considerable confusion with the functionality of the Wii U gamepad controls, struggling to locate the elusive but indispensable ' $z$ ' button, with few understanding how to open up the menu screens allowing players to tweak setting and save progress, or how to access the game map to assist in navigating the game territory. That all these functions were unfamiliar to participants and, as a result, greatly under utilized in their gameplay, renders the 'digital native' presupposition more of a hindrance than a help to classroom-based research that relies on a technological skill set.

\subsection{Games and gender}

As expected, based on our own and others' prior studies, we observed greater initial competence with 
the technology and requirements of the game by male students, more of whom reported playing games regularly, so that novice players in all-boy groups could and did learn from their more experienced fellows. Similarly reinforcing findings about play habits, experience and ability of girls [5], a significant advancement in both competence and confidence was observed among returning female participants of Phase Three as they assumed the role of 'expert' in all-girl settings that had been unavailable to them in mixed sex settings. All play groups advanced significantly further through the game when playing in all-girl settings, and in their exit interviews Phase Three participants remarked on their own improvement, expressed satisfaction with their performance and were markedly better able to articulate the game's narrative, making this configuration the most successful in addressing study goals than either of its predecessors

\section{Concluding Remarks \& Reflection}

We started out by asking what we really know about the educational value of students playing commercial games, particularly when their play has little explicit, didactic or pedagogical mediation or other 'teacherly' intervention. Looking specifically at one foundational curriculum area, the development of narrative competence [7], we wanted to design a study that could provide evidence one way or another of whether and how narrative competence could be developed or supported by having students play a story-driven, narratively framed game. At many points in the study we found ourselves focusing, instead, on those factors and conditions impeding precisely the learning achievements we had set out to study. Running this lunchtime games project shed valuable light on specific issues that effect learning with games, and our ability to study that learning so as to generate persuasive evidence of its educational value. These insights are helpful in shaping the design of our own research, and we hope they may prove useful for other researchers in the field to consider. They highlight important issues of access, both in terms of the legibility of game narrative as participants tended to focus on the mechanics of play over the story undergirding their play activity, and in terms of the technologies of play. Many of our most (self-declared) game literate participants (majority male) struggled with the novel hardware while those who professed less experience (majority female) initially fell behind, demonstrating that these 'digital natives' need some time to 'migrate' to new devices and systems. We saw how easy it is to suppose we are studying students' play, when in fact we are missing out the girls. We were able to observe behaviour that challenges some core assumptions about the learning potential of games: we had expected participants to play in conventional and productive ways, and we expected them to be motivated by the games designed progression system. We even offered them a template (walkthrough) for this play, and yet participants deviated, diverted, and experimented. Our own assumptions and the actions we observed underscored a need to think more deeply not only about what makes a "good" game for learning [12], but just as much about how to design and scaffold the kind of "good" play through which that learning might be realized. Based on the three iterations of the project we described above, in which no significant subject-matter learning was in evidence until we implemented direct instruction within each play session, and worked with a collaborative and compliant (all-girl) group, we are left with the question of whether good play of the kind conducive to school learning just might be more like school, and less like play.

\section{References}

[1] Ahearn, L, "The Legend of Zelda: The Wind Waker Retrospective Review", Game Cloud, $<$ http://gamecloud.net.au/featured/featured-review/thelegend-of-zelda-the-wind-waker-retrospective-review $>$

[2] Akkerman, S., Admiraal, W., \& Huizenga, J. "Storification in History Education: A Mobile Game in and About Medieval Amsterdam", Computers \& Education, 52, 2009, pp. 449-459.

[3] Barab, S. "Design based research: A methodological toolkit for engineering change", The Cambridge Handbook of the Learning Sciences, $2^{\text {nd }}$ Edition, R. K. Sawyer, (Ed.), 2014, pp. 151-170.

[4] Barab, S., Dodge, T., Jackson, C., \& Arici, A., "Technical Report on Quest Atlantis (Vol. 1)", Center for Research on Learning and Technology, 2003.

[5] Barab, S., Thomas, M., Dodge, T., Carteaux, R., \& Tuzun, H., "Making Learning Fun: Quest Atlantis, A Game Without Guns", Educational Technology Research and Development, 53(1), 2005, pp. 86-107.

[6] Carr, D., "Contexts, Pleasures and Preference: Girls Playing Computer Games", Digital Games Research Association Conference, Changing Views: World's in Play, Vancouver, Canada, 2005.

[7] Culler, J., "Story and Discourse in the Analysis of Narrative", The Pursuit of Signs. Semiotics, Literature, Deconstruction, Cornell University Press, Ithaca: New York, 1981, pp. 169-187. 
[8] Curry, K., "Warcraft and Civic Education: MMORPGs as Participatory Cultures and How Teachers Can Use Them to Improve Civic Education", The Social Studies, 101(6), 2010, pp. 250-253. http://doi.org/10.1080/00377990903493879

[9] Delwiche, A., "Massively Multiplayer Online Games (MMOs) In the New Media Classroom", Educational Technology \& Society, 9(3), 2006, pp. 160-172.

[10] Dicky, M. D., "Game Design Narrative for Learning: Appropriating Adventure Game Design Narrative Devices and Techniques for the Design of Interactive Learning Environments", Association for Educational Communications and Technology, 54(3), 2006, pp. 245-263.

[11] Dickey, M. D., "Murder on Grimm Isle: The Impact of Game Narrative Design in An Educational Game-Based Learning Environment", British Journal of Educational Technology, 42(3), 2011, pp. 456-469.

[12] Gee, J. P., "What Video Games Have to Teach Us About Learning and Literacy", Computers and Entertainment, 1(1), 2003, pp. 20. [12] Gee, J. P. Good Video Games and Good Learning: Collected Essays on Video Games, Learning and Literacy. Peter Lang, Bern: Switzerland, 2007.

[13] Gee, J. P. Good Video Games and Good Learning: Collected Essays on Video Games, Learning and Literacy. Peter Lang, Bern: Switzerland, 2007.

[14] Golding, D., "Putting the Player Back in Their Place: Spatial Analysis From Below", Journal of Gaming and Virtual Worlds, 5(2), 2013, pp. 117-130.

[15] Kafai, Y.B., "The educational potential of electronic games: From games-to-teach to games-tolearn”, Playing By the Rules, Cultural Policy Centre, University of Chicago, 2001. $<$ http://culturalpolicy.uchicago.edu/sites/culturalpolicy. uchicago.edu/files/kafai.pdf $>$

[16] Lechevallier, M., "The Legend of Zelda: The Wind Waker HD”, Slant Magazine, 2013 $<$ http://www.slantmagazine.com/games/review/thelegend-of-zelda-the-wind-waker-hd $>$

[17] Linderoth, J., “Why Gamers Don’t Learn More: An Ecological Approach to Games as Learning Environments", Journal of Gaming and Virtual Worlds, 4(1), 2012, pp. 45-62.
[18] Novak, E., "A Critical Review of Digital Storyline Enhanced Learning", Education Tech Research Dev, 63, 2015, pp. 431-453.

[19] Ministry of Education, "The Ontario Curriculum Grades 1-8 - $\quad$ Language", 2006. http://www.edu.gov.on.ca/eng/curriculum/elementary/l anguage 18currb.pdf

[1920] Murray, J. "Hamlet on the Holodeck", MIT Press, Boston: Massachusetts, 1998.

[22] Prensky, M., "Digital Natives, Digital Immigrants." On the Horizon, 9(5), 2001, pp. 1-6.

[22] Riendeau, D., "The Legend of Zelda Wind Waker HD Review: Sail Away", Polygon, 2013 $<$ http://www.polygon.com/2013/9/18/4743554/thelegend-of-zelda-the-wind-waker-hd-review-sailaway $>$.

[23] Shultz Colby, R., \& Colby, R., "A Pedagogy of Play: Integrating Computer Games into the Writing Classroom", Computers and Composition, 25, 2008, pp. 300-312.

[24] Steinkuehler, C. A., "Cognition and Literacy in Massively Multiplayer Online Games", Coiro, J., Knobel, M., Lankshear, C., \& Leu, D. (Eds.), Handbook of Research on New Literacies, Taylor \& Francis, Oxford: United Kingom, 2008, pp. 611-634.

[25] Steinkuehler, C. A., "Learning in Massively Multiplayer Online Games", Kafai, Y. B., Sandoval, W. A., Enyedy, N., Nixon, A. S., \& Herrera, F (Eds.), Series). Teachers College Press, New York: New York, 2011.

[26] Thomas, M. K., Barab, S. A., Tuzun, H. "Developing Critical Implementations of TechnologyRich Innovations: A Cross-Case Study of the Implementation of Quest Atlantis", Education and Educational Research, 41 (2), 2009, pp. 125-53.

[27] Trautman, T., “It's-A-Me, Ishmael”, The Paris Review. 2015 $<$ http://www.theparisreview.org/blog/2015/03/25/its-ame-ishmael/>

[28] Young, M. et al., "Our Princess is in Another Castle: A Review of Trends in Serious Gaming for Education", Review of Educational Research, 82(1), 2011, pp.61-89. 